\title{
LOS PEREIRA DE CASTRO MONTENEGRO DE ARCOS EN TUI
}

\author{
Por \\ ERNESTO IGLESIAS ALMEIDA
}

Esta antigua familia de origen portugués constituyó una de las más ilustres de la nobleza tudense de finales del siglo XVI. Magníficamente estudiada por Valdés Costas ${ }^{1}$, quisiéramos en este trabajo evocar sus más excelsas glorias gracias a los interesantes datos que nos suministra la escritura de institución del vínculo y mayorazgo realizada por el Licenciado Paulo Pereira de Castro de Sousa y su esposa doña María de Montenegro en 1608 en favor de su única heredera, su hija doña María Pereira de Castro y Montenegro. Documento varias veces citado por los investigadores pero que había permanecido inédito hasta el presente ${ }^{2}$.

Como ya hemos dicho, el origen de este noble apellido proviene de la antigua casa y torre de la Camposa, en la montaña de San Pedro deArcos, Reino de Portugal, cuyo nombre y origen lo traspasa a las inmediaciones de la ciudad de Tui, en Randufe, con la homónima casa y torre de Arcos, de la cual hoy en día tan sólo se conservan sus restos en su portalón de entrada y escudos, en el mismo portalón y en la reconstruida iglesia de La Guía perteneciente a la antigua capilla que se encontraba en las inmediaciones de la misma casa ${ }^{3}$.

\footnotetext{
' FERNÁNDEZ-VALDÉS COSTAS, Manuel: Familias Antiguas de Tuy, págs. $97-$ 102. Pontevedra, 1958.

${ }^{2}$ Protocolo de Andrés Ferreira (9) fol. 142-182. 1608. Archivo Catedral de Tui.

${ }^{3}$ Prot. Andrés Ferreira 19 Mar. 1618, fol. 227.A.C.T. Testamento del Lic. Paulo Pereira de Castro, Canónigo Doctoral. En el mismo se indica que este lugar de Arcos lo había comprado a Basquida Garçia de Montenegro, mujer que fuera del Lic. Cadaval su tío.
}

"CUADERNOS DE ESTUdIOS GALLEGOS", Tomo XLVII, Fascículo 112, Santiago 2000. 
De la estirpe de los Pereira de Castro y personas muy relacionadas con la misma salieron dos grandes figuras de la intelectualidad de aquella época: D. Francisco de Caldas Pereira y Castro, Catedrático del Colegio Mayor de Santa Cruz de Coimbra, Oidor de la Chancillería de Oporto y Consejero del Rey. Su obra sobre Jurisprudencia fueron impresas en Lisboa, Coimbra, Amoeres, Lyón, Francfor, etc.

D. Álvaro de Cadaval Valladares y Sotomayor, también conocido por el nombre de «Cadavalo Gravio Calidonio Tydense», hermano de $D^{\mathrm{a}}$ Francisca Cadaval y Sotomayor, esposa de D. Antonio de Caldas Pereira de Castro, Señor de la casa de Arcos, fue un notable poeta y distinguido maestro de la Universidad Compostelana, cuya estatua figura sobre el frontispicio de la fachada de la misma.

El primer miembro conocido de esta familia tudense es el ya referido don Antonio de Caldas Pereira de Castro Sousa y Magallanes, Caballero de la Orden de Santiago y la de Cristo en Portugal, quien casa con doña Francisca Cadaval, hija de don Juan de Cadaval, Regidor Perpetuo de Tui y doña Ana Álvarez Barbosa.

D. Antonio de Caldas Pereira de Castro fallece como Comendador en Tui el 11 de diciembre de 1592, siendo enterrado en el panteón que la familia tenía con sus armas en el Claustro de Santo Domingo de Tui ${ }^{4}$.

Fruto de este matrimonio son:

- D. Paulo Pereira de Castro y Cadaval, Caldas, Sousa, Magallanes, Valladares y Sotomayor, Señor de la Casa de Arcos.

- D. Francisco de Caldas Pereira y Castro, que pasa a Portugal, tal como hemos visto, casado con doña Ana de Rocha.

- D. Juan Pereira de Castro, que pasa al Brasil al servicio del Rey.

\footnotetext{
${ }^{4}$ Tumbo Nuevo de Santo Domingo (335), fol. 73. 1698. A.C.T. «Sepultura en el claustro de D. Antonio Montenegro. Sobre la sepultura que está en el claustro junto a la puerta de Gracias en el dia de las Animas se dice una misa cantada con ministro en el altar de piedra en donde está $\mathrm{N}^{\mathrm{a}} \mathrm{S}^{\mathrm{a}}$ en talla de piedra, paga 12 rls., un carnero y una buena ofrenda. Dicen que el entierro es suyo porque tiene sus armas por que la conpraron sus antepasados...».
}

"CUADERNOS DE ESTUDIOS GALLEGOS", Tomo XLVII, Fascículo 112, Santiago 2000. 
Don Paulo casa con doña María de Montenegro y ambos constituyen el vínculo y mayorazgo de Arcos, del cual es heredera su única hija doña María Pereira de Castro y Cadaval que casa en Tui el 17 de febrero de 1608 con don Lorenzo Montenegro y Sotomayor, Oca, Sarmiento, Mariño de Lobera, natural de Pontevedra, hijo de D. Pedro de Montenegro y $D^{a}$. Clara de Mendoza, era Regidor de Tui. Desde entonces quedan unidas estas dos importantes casas nobles del Sur de Galicia.

Don Paulo fallece en Tui, viudo siendo canónigo de la Catedral, el 5 de marzo de 1618. Fue enterrado en la Capilla de las Angustias de la Cate$\mathrm{dral}^{5}$. Su esposa doña María de Montenegro había fallecido con anterioridad, el 20 de octubre de 1609, siendo sepultada en el panteón de Santo Domingo de la misma ciudad.

Fruto del matrimonio entre don Lorenzo de Montenegro y $\mathrm{D}^{\mathrm{a}}$. María Pereira de Castro son:

- D. Payo y Da . Clara, gemelos, baut. 22 de Ene. 1614.

- Da. María, baut. 10 Mar. 1616.

- D. Antonio Montenegro, Sotomayor, Pereira de Castro, baut. 12 May. 1617 q.s.1.1.

- D. Lorenzo, baut. 15 Ago. 1622.

- D. Pedro, baut. 8 Oct. 1624.

-D. Manuel, baut. 15 Ene. 1626.

- $\mathrm{D}^{\mathrm{a}}$. Isabel, baut. 11 Jul. 1627, monja en el convento de las Agustinas Recoletas de Villagarcía, fall. en 1712 en olor de santidad.

\footnotetext{
${ }^{5}$ A pesar de que en su testamento se manda enterrar en Santo Domingo, éste se hace en la capilla de la Virgen de las Angustias de la Catedral, según se indica en la partida de defunción. Esta capilla estaba situada a la entrada principal de la Catedral, a la mano derecha, donde se encuentra la subida para el triforio, según se indica en la escritura de Mayorazgo.
} 
- $\mathrm{D}^{\mathrm{a}}$. Teresa, baut. 16 Dic. 1628 , al igual que su hermana monja en Villagarcía, fall. en 1687 en olor de santidad.

- Da. Josefa, baut. 15 Abr. 1632.

Don Antonio Montenegro casa con $\mathrm{D}^{\mathrm{a}}$. Francisca de Lemos y Sotomayor.

\section{ESCRITURA DE FUNDACIÓN DEL VÍNCULOY MAYORAZGO}

En ella aparece el Lic. Paulo Pereira de Castro y $D^{a}$. María de Montenegro como vecinos de Tui, diciendo:

"considerando que los / vienes y patrimonios partidos por grandes que sean en breve tienpo se acaban y/peresçen y ansi a este proposito dize la scriptura / debina que a un todo reino en si dibidido en / poco tienpo se acava y de la dibision rresultan grandes inconbenientes $y$ por ellos se pier / den y destruyen las familias y casas anti / guas y se acaba la dignidad y memoria de las / personas nobles y por el contrario de la / union que por los mayorazgos se aze y bin / culos y probisiones dellos andando los bienes / juntos e unidos y enteros en un cuerpo I de bienes inpartible y en una sola persona / y cassa se perpetuan y la memoria y antigua / nobleza de los passados y mayores dura / y permanesçe en el mayorazgo y subcesores / del como mas poderoso y ansi se con / serban y resplandezen en las familias / y esto sea sienpre seguido y sigue en las republicas muy grande vien y venefiçio publico /y particular entre todas las gentes y naçiones / para serbiçio de dios $y$ probecho comun y parti / cular dellas y aiuda de los otros hermanos $y$ / parientes pobres y para serbiçio de los señores / rreyes naturales y defensa de sus tierras y rey / nos...».

Dicho mayorazgo había sido aprobado por el Rey Felipe III, tal como se indica en el mismo:

«... y para mas / firmeza y autoridad de esta instituçion / pedido y suplicado a su magestad El Rey don Phelipe / terçero nuestro señor 
nos conçediese la açeça y facultad para ellos nos hizo mu / dar su çedula rreal de deligençias cometida al alcalde / mayor de gondomar... fecha en Madrid A / postrero de henero de mill y seisçientos y siete / años...».

Sobre la calidad de las personas se indica:

«... personas hijasdalgo notorios / muy linpios y de linpia noble sangre y de / mucha qualidad y nobleza y descendientes / dellos y que el padre del dho liçenciado pereyra / que fue del abito y caballeria de Xpo por / ser personas de mucha quenta y prendas / y de la dha calidad serbiçio a la catolica magestad / del Rei don Phelipe de santa memoria / nuestro señor En las ocasiones de guerra y sus / çesion del rreyno de Portugal y junto de / la persona y consejo del Conde Don Pedro / de Castro quando En esta ocasion tubo / por su cargo las cossas de guerra de todo el Partido / deste rreyno y el de Duero y Miño y por ello / le hizo su magestad algunas merçedes El y otros sus I mayores fueron caballeros hijos dalgo de / los libros y cassa rreal del dho rreyno y el dho / licenciado Pereyra de Castro su hijo fue en la misma / ocassion auditor general de dicho conde / y tanvien exerçio el dho oficio de auditor / de las galeras que en aquellos tienpos es / tubieron por esta costa y en las mas ocasiones / que despues an aubçedido a serbiçio de vtra magestad / y tenido de los ofoçios prinçipales de la re / publica de la dha ciudad y alcalde mayor en ella...»

Se nombra como heredera a su única hija $\mathrm{D}^{\mathrm{a}}$. María Pereira de Castro y Montenegro que era de edad de 16 años, para lo cual se transcribe la cédula Real firmada de los señores presidentes de Castilla y del Consejo de Cámara:

«... el tenor della qual / es como sigue / Don Phelipe por la graçia de Dios / Rey de Castilla, de Leon Aragon de las dos / Sizilias de Jerusalem de Portogal de Nabarra de Granada de Toledo de Valençia de Galizia de Mallorca de / Sebilla de Cerdeña de Cordoba de Corzega / de Murçia de Jayen de los Algarbes de Algecira / de Gibraltar de las Yslas de Canaria de la Yn / dias Orientales y Oçidentales Yslas y tierra / firme del mar oçeano y archiduque de Ma / yorca duque de Borgoña de Brabante y Mi / lan conde de Abspurg de Flandes de Tirol 
/y de Barcelona Señor de Biscaya y Molina / E por quanto por parte de vosotros El Liçenciado Paulo Pereira de / Castro y Dona Maria de Montenegro su muger / vecinos de la çiudad de Tuid nos a sido echa / relaçion que los bienen muebles y rrayzes / juros censos y eredamientos y otros qua / lesquiera vienes que al presente teneys y / tubieredes adelante o de la parte que dellos os / paresçiere queriades hazer mayorazgo / en dona Maria Pereira de Castro Montenegro / Buestra hija unica unibersal herede / ra y en sus descendientes supplicando nos / fuesemos servidos de daros facultad ntra / para ello o como la ntra merçed fuese / nos acatando lo suso dicho y los serviçios / que vos el dho Liçendo Pereira hizistes al / Rey ntro Señor que sancta gloria / aya en lo de Portogal siendo auditor / del exerçito q el Conde de Lemos Don / Pedro de Castro tubo a su / cargo en las partidas de Gondomar Duero / y Miño de las galeras que ubo en la / costa de Galizia y esperamos que nos / areys y an los que asimismo hizo en la / dha ocassion y çerca della persona del / del dho conde Antonio de Caldas Pereyra buestro / padre caballero que fue de la Orden / de Xpto y a que lo usa buestra hija...»

En el documento se van señalando los diferentes bienes muebles e inmuebles del mayorazgo:

«... portanto ponemos ante todas cossas / en este binculo y mayorazgo de los bienes / que rresçivimos dio de su mano ave / mos resçivido para devoçion y adorno / de la nuestra hija y susçesores un / Rosario de cristal de nuestra Señora Rey/na de los çielos con nuebe piedras $y$ ex / tremos de oro y una cruz de oro / esmaltada pendiente y con una corneza / je monteria de oro pendiente con sus ca / denillas de oro y con un agnus dey / de oro del otro lado todo valor de / quinientos rreales encargando como en / cargamos su deboçion a nuestros subce / sores para que por los meritos del / dho rrosario de nuestra señora se con / serven y lo en esta fundaçion hordenado / Yten ponemos y tenemos / en este mayorazgo y para fundamento del / don que se conserbe la ntra / hermita de nuestra Señora de la Guia / y Remedios echa y fundada en nuestro lugar / de Arcos dentro de los limites de la pa / rroquia desta çiudad para que ella / e lo que hordenamos sienpre nos guie y a / nuestros subçesores cuyo rreparo y or / nato decente les 
encargamos y man / damos perpetuamente para que/sienpre este bien adronada confor / me agora la tenemos y mandamos se diga / en ella una misa semanaria de / de nuestras en todos los sabados del / año perpetuamente para la qual sien / do dios serbido dexaremos rrenta sena / lada y conparada por ssi y en el en / tretanto se diga y Repare a costa de / nuestros bienes y ansi mesmo en / cargamos a los dhos nuestros subçe / sores procuren y tengan sienpre / cuydado e la cofradia de nuestra Sra. / que en la dha hermita havemos yns / tituydo y traydo jubileo per / petuo e se conser / be para que el serbiçio de dios / y de nuestra Señora baya siempre / adelante... Yten ponemos en este dho mayorzgo nuestra capilla de nuestra / señora la mayor que tenemos y / avemos echo en el claustro del mo / nasterio de Santo Domingo desta çiudad / en la boveda de la pared junto / a la puerta del dho claustro que sale / para la dha iglesia y contigua con un mo / numento alto que alli tenemos y a / bemos echo y renobado en el lugar / premynebte por titulo que tene / mos de todo ello del dho convento / en el qual estan las armas de nuestras / generaciones y familias y respeto / desta capilla y sepulturas y por derecho de / todo ello ansimesmo tenemos / a prohibiçion del capitulo pre / çedente y mandamos ande todo junto e yncorporado en nuestra cassa y mayorazgo.

Yten nonbramos por nuestra cassa / y solar deste nuestro mayorzago la / nuestra cassa y torre del nuestro / lugar de arcos de la parroquia desta çiudad en / la qual lo fundamos y senalamos por / cassa y cabeça prinçipal de la donde / Antonio de Caldas Pereira nuestro / padre que santa gloria aya tenido y tras / passo la cassa antigua de uno de sus / solares que era la torre y cassa de la / canpossa en la montana de san Pedro / de Arcos rreyno de Portogal y con / todo lo a la dha cassa anexo y pertenes / ciente que al presente alli tenemos y / posehemos que son los bienes siguientes / con todos sus frutos y rentas de pan / y vino castaña y todo genero de / fruta y agoas derechos açiones y serbidun / bres y fuentes y rrobledos».

Se van detallando los diferentes campos y propiedades cercanos a la referida casa de Arcos.

Se especifica la casa donde vivían en la ciudad de Tui que estaba situada junto a la llamada «Porta da Pía» y que correspondería a las que poste- 
riormente fueran propiedades de los Montenegro y que en los años 1950 se deshicieron para construir el Cine Yut. Figurando, en la fachada que daba a la plazuela de las Monjas, dos escudos de armas: uno, que con toda probabilidad, representaba a los Pereira de Castro y el otro, de mayores dimensiones, con las alianzas de los Montenegro, sus nuevos propietarios, cuya casa reconstruyen el 10 de Enero de $1675^{6}$, cuya descripción junto con la de otras propiedades es la siguiente:

«... Yten la ntra casa / y torre de dos sobrados con su patio / en medio y enxido detras en que mo / ramos en esta çiudad junto de la puerta / prinçipal de la dha çiudad que llaman de / la pia que sale con la delantera a la calle / publica y por uno de los lados parte con / cassa del Liçendo Francisco Teixeira y por el otro lado con cassa de Francisco Marino boticario / y luego sale la dha ntra cassa por el mesmo / lado del Oriente a la calle publica que va / a la plaça desta çiudad para la plaçuela q / esta delante las cassas que fincaron del / Liçençiado Gortazar que agora son del Cabildo / desta çiudad y ansi mesmo para aquel / lado parten con cassa de Alonso Martines y a la parte del Norte sale la dha / ntra cassa y huerta della con su trasera / al callejon que va para la muralla en / tre las dhas nuestras cassas y la que finco del / dho Liçençiado Gortazar las quales dhas ntras / cassas son de fuero de la dignidad obispal / desta catedral y se paga por ellas en / cada un año çinco rreales y el derecho en / feteotico y de rrenobaçion que en ella / tenemos y los mejoramientos y per / fectos dellas que abemos echo y nuestros / anteçesores en la dha cassas aziendolas / y rreedificandolas de nuebo y conprando / las a las personas que las avian echo y / subçesores y tanvien a la dha dignidad / episcopal lo ponemos todo ello como / vienes propios nuestros en el dho / mayorazgo. Yten otra cassa so / brada diezmo a diso

\footnotetext{
${ }^{6}$ Véase nuestro trabajo: «En Torno al primitivo núcleo urbano de Tui», en el boletín Museo y Archivo Histórico Diocesano de Tui, págs. 155-58. Tomo V, 1989. En el solar de esta casa estuvieron situados los antiguos Palacios Episcopales de la Oliveira. El Lic. D. Paulo, en su testamento dice: "estando casado con mi muger conpre las cassas y palaçios en que vivo que costaron mas de 700 ducados». En la escritura de mayorazgo con referencia a las mismas dice que eran de fuero de la Dignidad Obispal de esta Catedral, lo que corrobora nuestra teoría.
}

"CUADERNOS DE ESTUDIOS GALLEGOS", Tomo XLVII, Fascículo 112, Santiago 2000. 


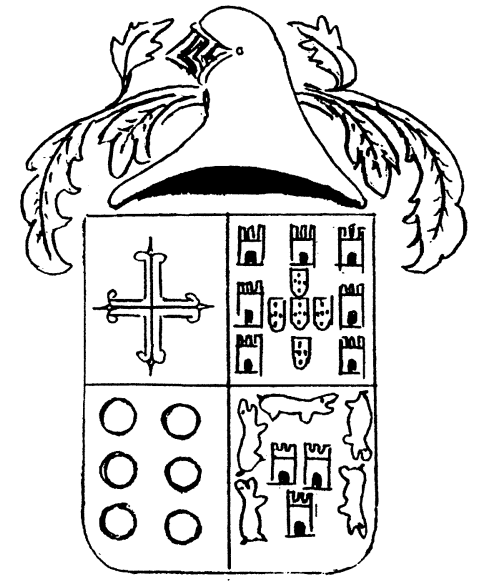

Escudo del portalón de entrada a la Casa de Arcos con los apellidos Pereira, Sousa, Castro y Lobato.

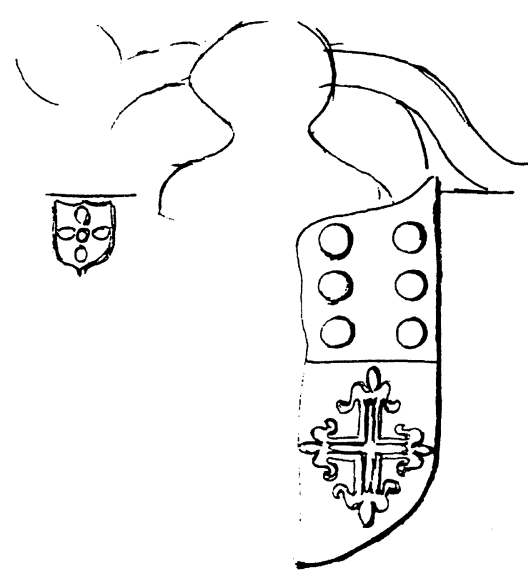

Restos del escudo de la casa con los apellidos Castro, Pereira y escusón de los Sousa.

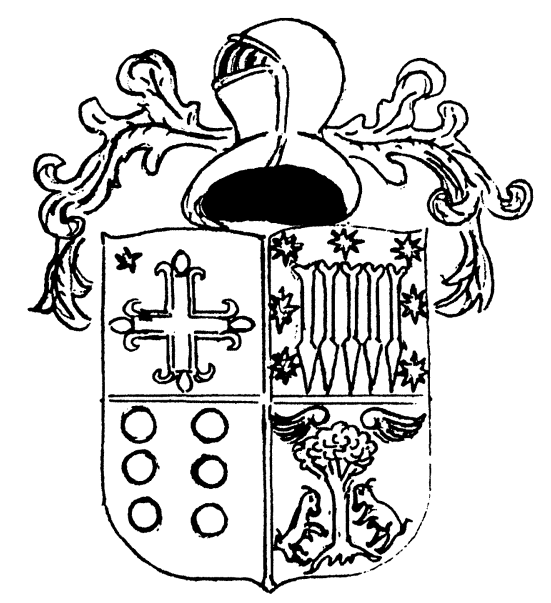

Escudo de la Capilla de Ntra. Sra. de la Guía con los apellidos Pereira, Yáñez, Castro y Cadaval. 
sin fuero censo ni tribu / to alguno que avemos y tenemos en la plaçuela que se dize del Poço frontero a la puerta / principal de la iglia mayor desta catedral / en que agora vibe por alquiler el al / calde mayor de la dha çiudad asi como / sale con su delantera para la dha plaçuela y de una lado parte azia el norte con / cassa q finco de Alonso de Penaranda / y de la otra parte hazia el me / dio dia con enxidos de dho Alonso de / Penaranda y lo mismo de la parte del / poniente. Yten metemos y pone / mos en este dho binculo y mayorazgo / la ntra cassa y torre de dos sobrados / que tenemos en la feligresia de San Tome / de Freixeiro jurisdiçion de la dha / villa de bigo con toda la granja y caserio / y bienes y rrentas y frutos agoas / y serbidunbres y aditiones a la dha cassa ane / xos y pertenesçientes la qual se dize / y nonbra la granja de Condomiñas / que son los vienes que a ella pertenes / çen los siguientes primeramente las / dhas cassas y torre don sus bodegas que / estan en los baxos dellas para reco / xer el vino de las viñas de la dha granja / con sus fustes y toneles $y$ pipas y / dos lagares de madera y cassas en que estan / y con su cavaleriça y paxar salido / y frontera della portada y con su / naranjal y limoneros y arboles...».

Se siguen detallando los diferentes bienes y propiedades, como viñas y huertas con plantaciones de muchos frutales situados en la misma parroquia de Santo Tomé de Freixeiro y en el propio Vigo, todo ello perteneciente a su esposa $\mathrm{D}^{\mathrm{a}}$. María de Montenegro y que habían sido aportados como bienes patrimoniales en su matrimonio.

A este mayorazgo añaden además otras alhajas de oro y plata:

"Primeramente una cadena de oro con siete / troços de oro esmaltados que / pesa mill y siete çientos y setenta / y seys rreales y de hechura doze duca / dos y un agnus dey tanvien de oro / della colgado de pesso y balor / y echura de çien rreales / Yten una fuente de plata dora / da de siete marcos de plata a çien rrls / El marco que costo siete çientos rre / ales. Yten un coutillon de oro para son / brero de mugery honbre o gorra con / treze pieças de oro esmaltadas y cada una / dellas con tres perlas blancas orienta / les y la rrosa de oro con su camafeo de / peso todas las dhas pieças y echura / de quatro çientos y cincuenta rreales. Yten otros dos contallos de plata / para dos sonbreros. 

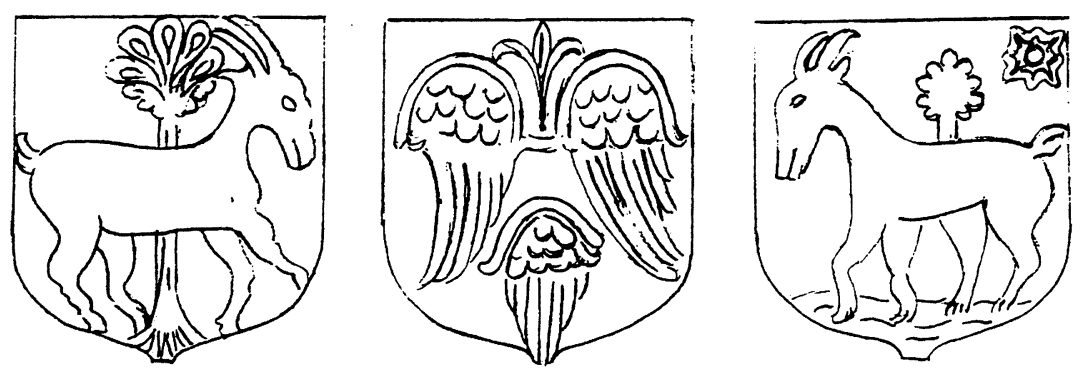

Escudos del arcosolio del claustro de Sto. Domingo de Tui con las armas de los Cadaval.

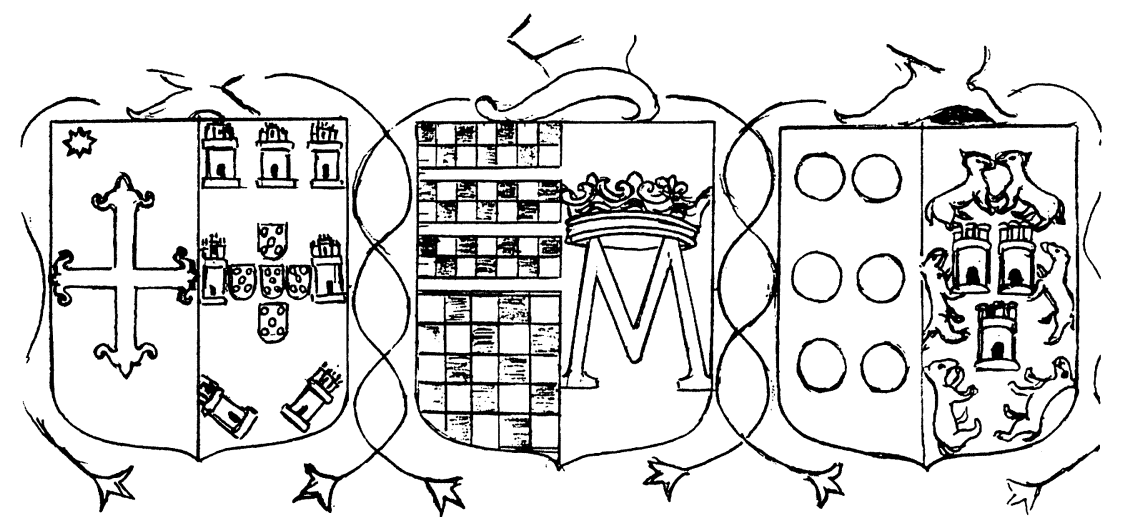

Escudos del arcosolio del claustro de Sto. Domingo de Tui con las armas de los Pereira, Sousa, Sotomayor, Valladares, Montenegro, Castro y Lobato. 
Yten una porçelana de plata dorada / con sus figuras de monteria que pesa / tres marcos siete honças y siete ota / bas que costo peso y echura y oro / diez ducados el marco. Yten una jarra de plata dorada / de peso de quatro marcos dos honças / y tres octavas pesso oro / y echura diez ducados por marco. Yten un salero de plata todo dorado en tres pieças con mucha / labor que pesa un marco seys / onças y siete octavas y el marco / al mismo preçio de diez ducados que / suma la plata de las tres pieças / porçelana jarro y salero diez marcos / y nuebe octavas que valen las octavas / nuebe rreales que son çien ducados y / nuebe rreales que otras tres pi / eças. Yten otra porcelana lisa toda do / rada que tiene tres marcos y medio / a nuebe ducados el marco pesso y echu / ra. Yten otro salero de plata dorado / de dos pieças de balor platay echura / de çiento y teynta y un rreales el peso / es marco y medio y una honça a siete / ducados y medio. Yten otra jarra blanca de plata de tres / marcos y una honça a ochenta rrls / por marco pesso y echura y ansi mesmo / otro xarro blanco de plata. esmaltado de dos asillas peso y echura / doze ducados. Yten dos candeleros de plata de pe / so de quatro marcos que agora estan / aziendo y dos tenedores tanvien de plata /. Yten una taça de plata blanca del / pie baxo del balor y pesso de setenta / Reales. Yten un apretador o gargantilla / todo de oro de qunze pieças con sus es / maltes y un rrobi en una dellas / de pesso valor u echura de quinientos / rreales. Yten una petrina para la dha / nuestra hija y suxçessores / que tubieren este mayorozgo fueren / cassadas con el que lo tubiere todo pa / su adorno echa y formada de doblo / nes biejos de dos caras de balor cada uno / de treynta rreales y uno grande de / sesenta rreales tanvien de dos caras / y otros doblones de quarenta y siete rrls / cada uno entremedidas las quales dhas / pieças muebles de oro y plata queremos y es / nuestra boluntad que tanvien anden unidas / e vinculadas con los mas bienes rra / yzes en esta escriptura...»

Se citan, como modelos de virtud y ejemplo, a sus antepasados, su padre Antonio de Caldas Pereira, Caballero de la Orden de Cristo, D. Luis González de Sousa, Comendador, su cuarto abuelo, Caballero del Consejo del Rey D. Alfonso V con título y residencia en su casa Real; a Alonso Pereira, su bisabuelo, Caballero del Consejo del mismo Rey e hidalgo de su casa y a otros antepasados cuyos nombres figuraban en las Cédulas 
Reales y papeles de los Archivos Reales del tiempo de Felipe II, los cuales tenían en su poder en dos libros encuadernados y firmados por notarios, los cuales les encargaban que fueran renovando en forma pública y se guardasen con todo cuidado los antiguos. Así mismo agregaban al vínculo varias piezas, armas de fuego y espadas, recuerdo de sus antepasados con un gran valor sentimental e histórico, que hablaban de sus participaciones en las batallas de Portugal y contra el invasor inglés Drake en la cuales habían intervenido:

"ponemos y metemos / en este vinculo y mayorzgo una espa / da ancha de caballo que el dho Conde don / Pedro de Castro dio a mi el dho Licençiado Pereira / en el canpo y Exercito de la entrada de / Biana Reino de Portogal en la dha ocassion / yendo junto de su persona como su auditor / del Exercito por el rrey nuestro Señor / q santa gloria aya y una escopeta / y un arcabuz que en la dha guerra ga / ne de los enemigos. Yten otro arcabuz y un murrion/grabado que gane a los enemigos yn / gleses erejes en el campo sobre bigo an / dando ellos quemando la iglesia y villa / estando en el puerto della la armada Real / Ynglesa de que bino por general Francisco / draques quando bino sobre Portogal / con donant pretenson del dho rreyrno / Yten una rodela dorada con su la / vacon dorada de la china que me dio el / marquez de Garres italiano passando / por aqui quando bino de la armada / de la guerra de Ynglaterra / de que fue general el duque de Medina / con mas dos ballestas de açero y to / do lo demas adereços de la gineta / y de cavallo que tengo en mi cassa / y las demas armas que tengo en / mis cassas susso declaradas y aya cuidado / de las azer linpiar y consumiendose / por el tienpo adelante se conpren otras y se bayan renobando para que / quando se ofresiere la ocassion de / enemigos y defensas de estoa rreynos / y la mas ocassion esten los dhos nu / estros subçesores aperçividos y tengan / en su cassa armas con que puedan salir / y acudir a ellas como yo y los dhos mis mayo / res sienpre abemos echo en defensa / de la fee y serviçio de nuestros rreyes / y señores como consta de las sertifi / caçiones de los generales de la dha cédula / Real y otros que tengo de los papeles de los dhos libros».

Ponían como condición expresa para las personas con que se casaren, hombres o mujeres, no fuesen judíos, cristianos nuevos ni sus des- 
cendientes, tampoco que fuesen moros o turcos, penitenciados del Santo Oficio de la Inquisición, o hijos naturales de clérigos o frailes. Solamente lo podían hacer con hijosdalgos o caballeros limpios sin «raza y sin mácula alguna». En caso contrario perderían el derecho a heredar el mayorazgo.

Se indica igualmente que en caso de juntarse dos mayorazgos, ambos anduviesen juntos sin que uno fuese dependiente del otro, poniendo el apellido de los Pereiras y sus armas y luego, en segundo lugar, el sobrenombre de su apellido. Lo mismo se guardaría en las armas, con el siguiente orden: Los que tenga por línea de varón en primer lugar, como son los Pereira y Sousas, luego los Castros y Caldas, y en tercer lugar, si se quieren añadir, los de otros apellidos de las propias generaciones y las de los maridos, según constaba en los papeles, informaciones y blasón del Rey de armas que tenían en los mencionados libros:

"y para / que en los tienpos venideros no aya dubida / en la aberiguaçion de las armas de nuestras familias y / campos y colores dellos declaramos que / los dhas nuestras armas son notorias / y estan algunas de ellas en los nuestros / monumentos y capilla de nuestra Sra la / mayor en santo domingo de esta çiudad dentro / en el claustro en dos monumentos altos / que estan en la bobeda de la / pared del dho / claustro devaxo de dos arcos en la dha pared / junto a la puerta que del dho claustro sale / a la Iglesia del dho convento y ansi mismo / estan en la nuestra hermita de nuestra / Señora de la Guia y rremedios en el dho ntro / lugar de Arcos y en las almenas de la çerca / y portadas del dho lugar y las armas / de linaje de Pereiras, es una cruz hu / eca floreteada colorada que apares / cio milagrosamente al autor de nuestro / linaje sobre una Pereyra dando la vatalla / de un rei moro con cuya vista fue / vençido y desbaratado por los nuestros y de la Pereyra / tomo el sobrenonbre, y de la cruz las ar / mas despues de ganada la victoria fa / mosa de los moros y el canpo della es / de plata, y las armas del linaje de Soussas son las çinco cuiñas / con siete torres alderredor ylas medias lunas cre / cientes de plata que se ganaron en la famo / sa batalla del canpo de Orique en / que fueron vençidos por el rei primero de Portogal / don Alonso enriquez a çinco reyes moros / y ganados çinco banderas y estandartes / que en efecto son çinco escudos pe / queños de colores azul con çinco roeles de / plata en sus 
escudos de plata a que co / munmente llaman las çinco cuiñas / q son las armas del rreino y rreys de Portogal / de donde vinieron a nuestros mayores / y ansi por constar dello las dio el Rey / darmas de dho Reyno a nuestra generaçion / del dho apellido como consta por bla / son del dho rreydearmas que tenemos / que esta en uno de los dhos nuestros li / bros de donde mas por estenso se puede / ver y entender esto, en quanto / a las armas de nuestro linaje de los de / Castro son seys rroeles azules tres de / cada lado en canpo blanco de argen / taria y plata como todo esto tenemos sacado / por mandado del Rey ntro Señor de sus libros y archi / vos de la Torre del Tonbo del dho rreyno de por / togal que del dho nuestro linajes dio el dho Rey / darmas que nos referimos, $y$ en quanto a las / armas de los Montenegros por linea derecha de / baron del padre de mi dha Ynstituyente y de / que sienpre avemos usado y nuestro mayorazgo / es una eme negra con los bordos de oro y una / corona ençima della, todo en canpo roxo / de sangre y ençima de la corona un yelmo çe / rrado, y aunque tenemos otras armas de / los otros nobles linajes donde proçedemos / no las ponemos aqui por no causar proligidad, y de ellas constan por / los papeles ariba dihos y libros de mano / que tenemos autenticos de que arriba se aze mençion...»

Continúa esta escritura de mayorazgo con otros términos técnicos sobre la sucesión en el mismo con una normativa muy estricta sobre repartos, pagos y alimentos a otros miembros de la familia, igualmente en lo que se refiere a delitos y prisiones en que pudieren caer los titulares del mayorazgo.

Ponen como condición las diferentes misas y días en que habían de celebrarse en su memoria y la de sus antepasados en la capilla de La Guía, Iglesia de Santo Domingo, Iglesia de Santo Tomé de Freixeiro y en la capilla de las Angustias de la Catedral, sobre la cual suplicaba al Obispo, Deán y Cabildo:

"... nos hagan de dar liçencia para que se pueda çerrar / con una rexa de hierro la dha capilla de nuestra / Señora de las Angustias de la dha Catedral $\mathrm{Pa} / \mathrm{ra}$ que queden dentro las dhas nuestras sepul / turas $y$ en todo por nuestra la dha capilla y queriendolo conçeder se de de limosna para la / fabrica treynta ducados con que se nos aga el titulo 
I de la dha capilla y en tal casso la rexa y pu / erta sera todo de valor de duzientos ducados y le supplicamos en tal casso hagan dezir las dhas missas / q arriba y abaxo yran declaradas / y sea el cavildo administrador perpetuo y / de la dha capilla y de la dha azienda de las obras / pias y sacrifiçios de susso y abaxo declarados y / patronos solamente de la dha capilla los aba / xo por nos nombrados y en tal casso se pon / dra la dha capilla con hornamento y rre / tablo deçente $y$ hornamentos para dezir las / missas en ella y asta el dinero y rrenta y todo / lo mas por nos declarado para las missas sa / crifiçios y obras pias se sacara en tal casso / de nuestros vienes y çensos dellos por la horden y forma en otro capitulo avaxo de / clarado...»

Se indica igualmente las misas que se habían decir en la iglesia de Santo Tomé de Freixeiro en donde estaban los enterramientos de los padres y antecesores de su esposa $\mathrm{D}^{\mathrm{a}}$. María de Montenegro:

"... se a tanvien de dezir una missa perpetua en la Iglia / de la dha feligresia de sto tome de Freixiero jurisdiçion / de la villa de Bigo en donde estan sepultados / los padres de mi la dha Instituyente en una / sepultura grande que esta dentro de la capilla / mayor junto con el altar que tiene las armas / de una de nuestras familias que es una / $M$ con su corona ençima para que sea / conosçida en todo tienpo y esta se dira en el / mesmo dia del Señor San Tome por las animas / de nuestros padres y madres de anbos y por / nos y nuestros subçesores como se dizen por los / dhos nuestros padres...».

Finalmente se nombra, entre los miembros de la familia, el orden que ha de regir com herederos en la sucesión del mayorazgo para el caso de que su hija no tuviese sucesión.

"CUADERnOS DE ESTUdios GALLEGOS", Tomo XLVII, Fascículo 112, Santiago 2000. 